\title{
A methodology for characterizing the electrochemical stability of DLC coated interlayers and interfaces
}

\author{
Emilija Ilic ${ }^{1,2}$, Ainhoa Pardo ${ }^{1}$, Thomas Suter ${ }^{1}$, Stefano Mischler ${ }^{2}$, Patrik Schmutz ${ }^{1}$, Roland Hauert ${ }^{1 *}$ \\ ${ }^{1}$ Empa, Swiss Federal Laboratories for Materials Science and Technology, Laboratory for Joining \\ Technologies and Corrosion, Switzerland \\ ${ }^{2}$ EPFL, Ecole Polytechnique Fédérale de Lausanne, Tribology and Interfacial Chemistry Group, \\ Switzerland
}

*Corresponding author: roland.hauert@empa.ch

\section{Abstract}

DLC coatings are often deposited on Si and Cr based adhesion-promoting interlayers to mitigate stress at the DLC/substrate interface. Interlayers reduce the likelihood of mechanical coating delamination. However, their chemical stability at miniature DLC coating defects, such as pores and micro-pinholes, may be adversely affected in a corrosive environment, such as the human body where DLC coated implants are envisaged. An experimental methodology is presented for accessing and characterizing the electrochemical reactivity of buried interlayers and interfaces. The interlayer, with its interfaces, is revealed by ion beam polishing at an angle, forming a wedge-like profile of the substrate/interlayer/DLC system. The chemical binding and composition of the interlayer/interface is determined by Auger electron spectroscopy (AES), and the susceptibility of the different interfaces to carbide formation and oxidation is identified. It is shown that pure interlayer/interface materials can be obtained for the model Co interlayer. On the other hand, for more reactive materials such as $\mathrm{Si}$, $\mathrm{Ti}$ and $\mathrm{Cr}$, the formation of new interface phases was observed.

This document is the accepted manuscript version of the following article: Ilic, E., Pardo, A., Suter, T., Mischler, S., Schmutz, P., \& Hauert, R. (2019). A methodology for characterizing the electrochemical stability of DLC coated interlayers and interfaces. Surface and Coatings Technology, 375, 402-413. https:// doi.org/10.1016/j.surfcoat.2019.07.055 
These different new materials are characterized for their corrosion susceptibility with a localelectrochemical microcapillary technique both at open circuit potential (OCP) and under potentiodynamic polarization. $\mathrm{Cr}$ and Si-DLC based interlayers presented good passive behavior, while a Si interlayer corroded in bovine-based wear test fluid (HyClone ${ }^{\circledR}$ WTF). An analogous degradation is found after a long-term immersion experiment and failed implant cases. The influence of coating defects distribution on the current response of DLC surfaces during electrochemical measurements was also investigated by varying the exposed area (from the $\mathrm{cm}^{2}$ to the $\mu \mathrm{m}^{2}$ range). Microscale characterization allowed for a better representation of the intrinsic reactivity of DLC, while larger areas were highly dependent on the underlying interlayer. 


\section{Introduction}

Hard coatings, such and titanium nitride (TiN) and diamond-like carbon (DLC), are promising materials for improving the wear resistance of articulating components, spanning from tooling to biomedical implant applications [1]. These coatings exhibit high internal residual stress when deposited directly onto a metallic substrate, which may result in premature delamination. To prevent this failure, adhesion-promoting interlayers such as titanium (Ti), silicon ( $\mathrm{Si}$ ), chromium (Cr), and a-C:H:Si (Si-DLC, deposited from tetramethylsilane), have been used to mitigate stresses at the coating/substrate interface [2]. Interlayers reduce the likelihood of mechanical coating delamination and many studies have investigated the influence of interlayers on the interfacial toughness of the system using various adhesion tests. For example, scratch tests and Rockwell indentations showed that Ti interlayers improved the adhesion of TiN coatings on substrates, due to strong Ti bonding with $\mathrm{N}$ atoms [3-5]. Rockwell indentations also showed that the addition of a $\mathrm{Cr}$ interlayer improved the interfacial toughness of DLC coated steel [6], and improved tribological properties such as low coefficient of frictions were demonstrated for $\mathrm{CrN}$ and $\mathrm{CCr}$ multi-interlayers [7]. Reciprocating wear tests on DLC coated steel demonstrated that samples with a Si interlayer provided greater resistance to delamination failure than samples with Cr interlayers [8]. Scratch tests further showed better adherence of DLC coatings on $\mathrm{Ti}_{6} \mathrm{Al}_{4} \mathrm{~V}$ substrates when a $20 \mathrm{~nm} \mathrm{Si}$ interlayer was used [9]. In other applications, Si interlayers have also been used to improve the electrical properties at the germanium/silicon dioxide interface of photonic devices $[10,11]$.

However, in the presence of a corrosive environment the mechanical integrity of these coated systems can be adversely affected. Although the hard coatings themselves are relatively inert, miniature defects in the coating such as pores and microscopic pinholes create entry points for 
the corrosive media to contact the underlying material. If the deposited interlayer or bonding interface is chemically unstable and susceptible to corrosion, this material will dissolve, resulting in coating delamination and failure of the component, as illustrated in the schematic of Fig. 1. For example, pits were observed at a TiN/stainless steel interface at locations where $\mathrm{NaCl}$ solution penetrated through columnar grain boundaries within the coating. Local galvanic coupling then occurred between the nobler TiN coating and more active substrate [12]. In physiological environments, some DLC coated articulating implants were retrieved after only a few years in patients. Cross-sectional FIB cuts into a retrieved $\mathrm{Ti}_{6} \mathrm{Al}_{4} \mathrm{~V}$ hip implant revealed that the Si adhesion promoting interlayer had completely dissolved at some locations, resulting in coating delamination and severe abrasion of the implant by DLC particles $[13,14]$. A retrieved DLC coated CoCrMo toe joint with a Si interlayer showed similar results [15]. In another failure case, the interfacial adhesion strength of Si-doped DLC coatings on stainless steel was reduced up to $75 \%$ when the samples were immersed in fetal calf serum [16]. Based on these observations, some studies have also focused on the chemical stability investigation of hard-coated surfaces. Macroscale (consisting of a characterization area in the $\mathrm{cm}^{2}$ range) electrochemical characterization methods such as potentiodynamic polarization and electrochemical impedance spectroscopy (EIS) have been extensively used to provide fast information about the corrosion susceptibility of coated metallic substrates. For dental applications, EIS was used to study the corrosion behavior in saline solution of DLC coatings on Ti-based substrates, with $\mathrm{Ti}$ and $\mathrm{Cr}$ interlayers [17]. The coated samples that included a $\mathrm{Cr}$ interlayer showed the highest resistance to charge transfer. Potentiodynamic polarization measurements were performed on 316L steel/DLC systems with various $\mathrm{SiN}_{x}$ interlayers and the corrosion protection behavior of the substrate increased with each deposited film [18]. Long-term immersion of 304L/TiN samples in $\mathrm{H}_{2} \mathrm{SO}_{4}$ showed increasing open circuit potential (OCP) over time, due to the high tendency of $304 \mathrm{~L}$ to passivate at 
coating defects. However, when a weaker passivating substrate such as Fe was used, the OCP of the Fe/TiN sample rapidly decreased to the same potential as that of bare Fe [19]. The influence of galvanic corrosion at interfaces was studied by depositing conducting TiN and $\mathrm{ZrN}$ coatings on an insulating glass substrate in order to measure their intrinsic corrosion potentials. The measured values were higher compared to the ones obtained when the coatings were deposited on steel. In this case nearly the same negative potentials as on the bare steel were obtained, the potential shift interpreted in terms of galvanic coupling and polarization of the nitride coating surface $[20,21]$.

As the macroscale electrochemical behavior is highly related to a convolution of the extent of coating defects, passivity of the underlying material, and the size of the exposed electrode area, determination of the coating porosity is essential in order to compare the corrosion resistance of different coated systems [22,23]. However, this information is often excluded from many corrosion studies, and hence comparison between different deposition batches and interlayers becomes restricted. Macroscale characterization on the coating surface is also not suitable to assess the corrosion mechanisms and stability of the actual buried interlayer/interface itself. The deposited interlayer will act as a new material with corrosion susceptibility characteristics different from that of the bulk material analog. Especially when the interlayer is a blend of more than one material, for example Si-DLC, or chromium carbide (Cr-C), that may also contain some contaminations (e.g. oxygen, carbon) from the deposition processes.

In this study, a methodology for characterizing the compositional makeup and the corrosion behavior of deposited buried interlayers based on a microscale electrochemical technique is introduced. The buried interlayer/interface is first revealed through ion beam polishing, and its composition is determined by Auger Electron Spectroscopy (AES) spectra recording and 


\section{Journal Pre-proof}

chemical component analysis. By utilizing a local-electrochemical technique (consisting of a glass microcapillary that acts as a miniaturized electrochemical cell), the interlayer is then characterized through precise positioning and subsequent OCP evolution and potentiodynamic polarization measurements, using a relevant physiological-simulating electrolyte to mimic the environment around a DLC coated implant. 


\section{Experimental}

\subsection{Materials and sample preparation}

Titanium disk substrates (99.5\% Ti, diameter $2.5 \mathrm{~cm}$, from Brütsch-Rüegger AG) were ground (320 grit CarbiMet SiC paper, Buehler) and polished (9 $\mu \mathrm{m}$ MetaDi paste, $0.06 \mu \mathrm{m}$ Master-Met colloidal silica, Buehler) to mirror finish according to the metallographic preparation standard for $\mathrm{Ti}$, ultrasonically cleaned in acetone then ethanol for $15 \mathrm{~min}$ in each agent, and dried under argon (Ar).

A custom-built $13.56 \mathrm{MHz}$ radio frequency (RF) plasma-activated chemical vapor deposition (PACVD) chamber (base pressure in the 1E-5 Pa range) was used for coating deposition. The RF power is capacitively-coupled to the sample holder and the power supply is regulated to maintain a consistent self-bias. Prior to deposition, the substrates were cleaned in situ for 30 min with Ar plasma with a flow rate of $19 \mathrm{~cm}^{3} / \mathrm{min}(3.5 \mathrm{~Pa})$ at $-600 \mathrm{~V}$ self-bias. Secondly, 60 - $100 \mathrm{~nm}$ adhesion promoting interlayers, cobalt (Co), chromium $(\mathrm{Cr})$ and silicon $(\mathrm{Si})$ were grown onto the substrates via magnetron sputtering with a target $(99.99 \%$ in purity of the respective material, from HMW Hauner GmbH \& Co. KG) using an Ar flow rate of 3 $\mathrm{cm}^{3} / \mathrm{min}(0.9 \mathrm{~Pa})$ at $60 \mathrm{~W}$. Hydrogenated amorphous silicon carbide, a-C:H:Si (denoted Si$D L C$ throughout the paper), interlayers were grown using tetramethylsilane (TMS), $\mathrm{Si}\left(\mathrm{CH}_{3}\right)_{4}$, gas at a flow rate of $9.6 \mathrm{~cm}^{3} / \mathrm{min}(0.6 \mathrm{~Pa})$. Lastly a $2 \mu \mathrm{m}$ DLC, a-C:H, coating was deposited using acetylene $\left(\mathrm{C}_{2} \mathrm{H}_{2}\right)$ gas with a flow rate of $7.2 \mathrm{~cm}^{3} / \mathrm{min}(1.5 \mathrm{~Pa})$ at a $-600 \mathrm{~V}$ self-bias. The coatings contained a hydrogen content of ca. 22 at\% (as measured by Elastic Recoil Detection Analysis), and an $\mathrm{sp}^{3}$ fraction of ca. 0.3 (calculated based on a hardness of $25 \mathrm{GPa}$ [24]).Throughout the paper, a sample will be denoted as substrate/interlayer/coating (for example: Ti/Si/DLC). The prepared and studied deposited samples are summarized in Table 1. 
Table 1: Summary of the prepared and studied deposited samples.

\begin{tabular}{|c|c|c|c|}
\hline Sample notation & Substrate & $\begin{array}{c}\text { Interlayer } \\
(60-100 \mathrm{~nm})\end{array}$ & $\begin{array}{c}\text { Coating } \\
(2 \mu \mathrm{m})\end{array}$ \\
\hline Ti/Co/DLC & \multirow{4}{*}{$\begin{array}{l}\text { Titanium } \\
\quad(T i)\end{array}$} & Cobalt $(\mathrm{Co})$ & \multirow{4}{*}{$\begin{array}{l}\mathrm{a}-\mathrm{C}: \mathrm{H} \\
(D L C)\end{array}$} \\
\hline $\mathrm{Ti} / \mathrm{Cr} / \mathrm{DLC}$ & & Chromium $(\mathrm{Cr})$ & \\
\hline $\mathrm{Ti} / \mathrm{Si} / \mathrm{DLC}$ & & Silicon $(\mathrm{Si})$ & \\
\hline Ti/Si-DLC/DLC & & $\mathrm{a}-\mathrm{C}: \mathrm{H}: \mathrm{Si}(\mathrm{Si}-\mathrm{DLC})$ & \\
\hline
\end{tabular}

After the coated samples were prepared, a three-step methodology was applied in which the buried interlayer was revealed and characterized by:

1) Ion beam polishing of the sample at an angle in order to expose and laterally widen the interlayer.

2) Chemical composition determination of the interlayer and its corresponding interfaces with the substrate and coating, by local and quantitative AES measurements.

3) Local electrochemical characterization of the interlayer material reactivity using a microcapillary technique in order to determine its corrosion susceptibility in physiological simulating solution.

The three characterization steps are further described in the following.

\subsection{Ion beam angled polishing (wedge-milling)}

In order to expose and access the buried interlayer material for compositional and electrochemical characterization, ion beam polishing was conducted on the coated samples with an IM4000 Ion Milling System (Hitachi). Using an Ar ion beam (6 kV accelerating voltage, $1.5 \mathrm{kV}$ discharge and $0.09 \mathrm{~cm}^{3} / \mathrm{h}$ gas flow), a "wedge-like" profile was sputtered into 
the sample, exhibiting a deeper center and shallower edges, as seen in the schematic of Fig. 2. The ion beam irradiation angle, referring to the angle formed by the axis of rotation (normal to the sample surface) and the beam's center axis, can be set from 0 to $90^{\circ}$. The eccentricity of the ion beam can be set from 0 to $5 \mathrm{~mm}$; the range of central uniform sputtering increases with larger eccentricity. For this study, different beam parameters were investigated, and an irradiation angle of $70^{\circ}$ and an eccentricity of 0 was chosen. These settings allowed for the lateral widening of the interlayer/interfaces, but not to the point where the vertical thickness of the interlayer (normal to the substrate) was too thin for post-characterization (as was the case with larger angles). The sample was ion polished until the substrate was reached and visually revealed. With these parameters, the substrate is exposed, and the interlayer spread laterally up to ca. 1000 times its deposited thickness. After this ion beam polishing procedure, the sample will be referred to as a wedge-milled sample, whereas the term coated sample will be used prior to the ion beam polishing procedure. The lateral width of the wedge-milled interlayers varied between the samples, as it is dependent on the time at which the ionic polishing was stopped (i.e. longer polishing results in a narrower interlayer). The ion polishing process was simply stopped once the substrate could be visually seen, so additional minutes between samples resulted in slight variations in the width of the exposed interlayer. It should be mentioned that some structural defects can be generated by the ion polishing process. On the other hand, it can be stated that Ar is inert so that the formation of different chemical compounds with very different passivation/electrochemical reactivity at the surface can be excluded.

\subsection{Auger electron spectroscopy (AES) analysis of the interlayer/interfaces}

Local surface characterization (chemical composition) was carried out with a Physical Electronics PHI 4300 scanning Auger microscopy (SAM) system operating at electron beam parameters of $5 \mathrm{kV}(30 \mathrm{nA})$ and with the cylindrical mirror analyzer at $0.6 \%$ energy 
resolution. AES measurements were performed with a lateral resolution in the micrometer range and a typical depth sensitivity of 2-4 $\mathrm{nm}$. The chemical composition of the wedgemilled interlayer/interfaces was determined by aligning 30 consecutive measurement points (with recording of all relevant element specific peaks) across the wedge-milled sample, from the Ti substrate, across the interlayer and into the DLC. As opposed to performing one conventional linescan, this approach allows for the collection of the relevant spectra at each specific point, providing more chemical binding information. The term multipoint-linescan will be used to refer to this approach. The area of analysis was pre-sputtered with a $2 \mathrm{kV} \mathrm{Ar}$ beam $(2 \times 2 \mathrm{~mm}$ raster size, $9.4 \mathrm{~nm} / \mathrm{min}$ sputter rate calibrated on a $100 \mathrm{~nm} \mathrm{SiO}$ reference film) for ca. $5 \mathrm{~min}$ before measuring in order to remove any native oxide layer formed after the wedge-milling of the sample. After collection of the raw spectra, the data was analyzed using MultiPak software (provided by Physical Electronics). The atomic concentration (at\%) at each point was determined from its derivative spectrum, based on software built in sensitivity factors.

In AES, when transitions involving core levels close to the valence band or even valence band electrons are considered, very important information about the chemical environment can be obtained in addition to the simple composition analysis. Well known examples of chemical binding analysis can be found for the $\mathrm{C}(\mathrm{KLL})$ and $\mathrm{O}(\mathrm{KLL})$ transition where the valence band electrons are involved [25]. These transitions are referred to as KVV transitions and the final state relaxation effects and induced kinetic energy peak shape changes can be linked to different oxides or carbides present on the surface. Therefore, for each element ( $\mathrm{Ti}, \mathrm{C}, \mathrm{O}$, and the interlayer element), linear least square fitting (LLSF) was carried out on the at\% composition curves in order to separate the different chemical states (such as carbidic forms) contributing to the spectra. Absolute identification of the formed compound based on Auger transitions is however difficult so that assigning peak shapes to reference spectra from known 
components is performed in this paper and this procedure allows, at least in a semiquantitative way, identification of the compound or element. In this study the peak shape structures were compared with previously published raw reference spectra, an example of an AES element spectra fitting is presented in section 3.2.

\subsection{Macro and local microcapillary electrochemical characterization}

Macro-electrochemical (consisting of a characterization area in the $\mathrm{cm}^{2}$ range) measurements where first conducted on two coated samples with different interlayers, Ti/Co/DLC and Ti/Cr/DLC, using a Metrohm-Autolab PGSTAT30 potentiostat. A three-electrode electrochemical cell was used with an exposed working electrode (WE) diameter of $0.5 \mathrm{~cm}$ (area of $0.2 \mathrm{~cm}^{2}$ ) and an electrolyte volume of $100 \mathrm{~mL}$. A 3M silver/silver chloride $(\mathrm{Ag} / \mathrm{AgCl})$ reference electrode (RE, from Metrohm) was used with a glass Luggin capillary as an electrolyte bridge and a platinum $(\mathrm{Pt})$ rod as the counter electrode (CE). A potential scan rate of $1 \mathrm{mV} / \mathrm{s}$ was applied for potentiodynamic polarization experiments. The macroscale measurements on the coated samples (before ion beam polishing) were compared to localelectrochemical (consisting of a characterization area in the $\mu \mathrm{m}^{2}$ range) measurements in order to demonstrate the influence of the characterization area size on the electrochemical behavior of a coated sample. Local-electrochemical measurements were performed with the microcapillary technique (an overview of the technique is presented by Suter and Böhni [26]). The technique utilizes a glass capillary filled with electrolyte whose tip diameter can be adjusted from ca. 1-1000 $\mu \mathrm{m}$ by heating and pulling. In these experiments, a tip diameter of $70 \mu \mathrm{m}$ (area of 3.85E-5 $\mathrm{cm}^{2}$ ) was used. The tip of the capillary is coated with silicone sealant, in order to confine the electrolyte within the characterization area upon contact with the WE surface. A $3 \mathrm{M} \mathrm{Ag} / \mathrm{AgCl} \mathrm{RE}$, was connected to the capillary through an electrolyte bridge tube, and a Pt wire CE was inserted into the capillary holder, as depicted in Fig. 3. A highresolution potentiostat (Jaissle 1002T-NC-3) with a current resolution of ca. $10 \mathrm{fA}$ was used. 
The microcapillary setup is mounted into a modified lens socket of an optical microscope and the WE is fixed onto the microscope stage. This arrangement allows for precise positioning of the microcapillary by optically locating the desired characterization area through an objective lens and then switching to the microcapillary cell with the revolving nosepiece. An external telescopic sight is utilized in order to approach and place the capillary tip onto the sample. In all electrochemical measurements HyClone ${ }^{\circledR}$ Wear Testing Fluid (HyClone ${ }^{\circledR}$ WTF, ThermoScientific) of $\mathrm{pH} 7.4$ was used as the electrolyte; it is bovine serum-based and designed to simulate human synovial fluid, containing all the relevant body ions (phosphate, chloride, etc.) and $30 \mathrm{~g} / \mathrm{L}$ of proteins.

The microcapillary electrochemical technique was then later applied for a more systematic local characterization of the wedge-milled samples, presented in sections 3.3 and 3.4. Two types of characterizations were conducted: i) $24 \mathrm{~h}$ OCP measurements on the substrate (Ti), interlayer and DLC area of the wedge-milled sample and, ii) potentiodynamic polarization measurements on each component using a $1 \mathrm{mV} / \mathrm{s}$ potential scan rate, starting in the cathodic domain at $-200 \mathrm{mV}$ from the corrosion potential $\left(\mathrm{E}_{\mathrm{corr}}\right)$, up to $1200 \mathrm{mV}$. A capillary diameter between 30-70 $\mu \mathrm{m}$ was used, depending on the lateral width of the wedge-milled interlayer.

It has to be mentioned that while $\mathrm{Si}, \mathrm{Cr}$, and $\mathrm{Si}$-DLC are all relevant interlayers commonly used in practice, the purpose of using Co as an interlayer was simply to create a very electrochemically active Ti/Co/DLC model sample, in order to validate the approach. However the chemical stability of the Co/DLC interface is definitely also of interest, as DLC coated CoCrMo implants are also found. 


\section{Results and Discussion}

\subsection{Electrochemical characterization of DLC surfaces on interlayers}

Macro and local electrochemical characterization was performed on the DLC coated surfaces with Hyclone ${ }^{\circledR}$ WTF and compared for two coated samples with interlayers; Co and Cr. The macro-electrochemical cell consisted of a WE diameter of $0.5 \mathrm{~cm}$, and the microcapillary used for these local measurements had a WE diameter of $70 \mu \mathrm{m}$. This comparison was performed in order to demonstrate the dependency of the characterization area (WE area exposed to the electrolyte) on the electrochemical response of a coated surface, and how it relates to coating defects. Fig. 4 shows the macro-electrochemical potentiodynamic polarization measurements (represented by solid lines) of the Ti/Co/DLC and Ti/Cr/DLC surfaces along with their respective local-electrochemical measurements (dashed lines). Firstly, considering only the polarization curves performed with the macroscopic cell; it is evident that the two solid-lined curves show very different behavior from one another and are highly dependent on the underlying interlayer material. Considering the macro-measurement on the Ti/Co/DLC (red solid curve) sample; it exhibits a relatively low corrosion current density ( $\mathrm{i}_{\text {corr }}$ ) of ca. $3.5 \mathrm{E}-8$ $\mathrm{A} / \mathrm{cm}^{2}$ due to the protection of most of the surface by the DLC coating and an $\mathrm{E}_{\text {corr }}$ of ca. -200 $\mathrm{mV}$. However, after small anodic polarization, a rapid increase in current occurs above ca. -70 $\mathrm{mV}$ from $2 \mathrm{E}-7 \mathrm{~A} / \mathrm{cm}^{2}$ to very active values of $1 \mathrm{E}-3 \mathrm{~A} / \mathrm{cm}^{2}$ where the measurement was eventually terminated. At $\mathrm{pH} 7.4$, Co is oxidized to $\mathrm{Co}^{2+}$ above a potential of ca. $-700 \mathrm{mV}$ (as indicated by the $\mathrm{Co}-\mathrm{H}_{2} \mathrm{O}$ Pourbaix diagram [27]). Relating this to the electrochemical behavior of the coated sample in Fig. 4, it can be seen that the observed "breakdown" potential lies well above $-700 \mathrm{mV}$, were Co becomes unstable. It then becomes obvious that the major current contribution is coming from the underlying activated Co interlayer, due to the presence of minature defects in the DLC coating somewhere within the characterization area, hence inducing rapid destabilization of the coated system. However if the deposited 
interlayer is a passive material, or is reacting with the coating or substrate to form a new material (such as a carbide), the electrochemical behavior and corrosion susceptibility of this underlying material is then not as predictable anymore. Observing for example the macroelectrochemical measurement of the Ti/Cr/DLC sample (solid black curve), there are many undefined features in the current evolution which cannot be directly correlated with either the coating, interlayer or substrate reactivity, and hence correlating the electrochemical response to coating defects becomes complicated. Initially, the curve exhibits a low current densities of ca. 7E-9 A/cm ${ }^{2}$ and an $\mathrm{E}_{\mathrm{corr}}$ of $-100 \mathrm{mV}$, followed by a short stable region, evidenced by a slight plateau in the current density (referred to as $i_{\text {plat }}$ throughout the paper), until ca. $150 \mathrm{mV}$. This can again be attributed to the overall protection provided from the DLC coating, but is also consistent with the good intrinsic passivation behavior of $\mathrm{Cr}$. In the neutral $\mathrm{pH}$ range, $\mathrm{Cr}$ is protected by a very stable Cr-oxide $\left(\mathrm{Cr}_{2} \mathrm{O}_{3}\right)$ film above a potential of ca. $-1210 \mathrm{mV}$ (as indicated by the $\mathrm{Cr}-\mathrm{H}_{2} \mathrm{O}$ Pourbaix diagram [28]). However, above ca. $200 \mathrm{mV}$, transpassive dissolution of $\mathrm{Cr}_{2} \mathrm{O}_{3}$ to $\mathrm{CrO}_{4}{ }^{2-}$ is thermodynamically possible [28]. Observing Fig. 4, it is around this potential $(150-200 \mathrm{mV})$ that the current starts to gradually increase during anodic polarization. Hence, this feature in the curve could be attributed to $\mathrm{Cr}$ electrochemical oxidation at coating defects. However, oxidation of $\mathrm{C}$ to $\mathrm{HCO}_{3}{ }^{-}$species is also postulated at this potential and $\mathrm{pH}$, considering the carbon Pourbaix diagram [29]. Although DLC itself is a mix of hydrogen and carbon and is considered to be inert [30], it can become destabilized with anodic polarization and contribute to the current response in the curve of Fig. 4. Therefore, it is difficult to decipher whether this oxidation current is a contribution of the DLC instability itself, or of the underlying Cr-based interlayer at local DLC coating defects. Without this knowledge, the chemical stability and efficiency of the interlayer cannot be determined. By significantly decreasing the characterization area on a coated sample, larger and corrosion critical defects in the coating can be excluded. The current response of the electrochemical 
measurement therefore becomes more representative of the intrinsic behavior of the coating itself. The distribution of defects and their influence on the current signal can then be better assessed by comparing electrochemical measurements performed with different characterization areas.

Observing the very different current evolution of the local microcapillary measurements in Fig. 4 (dotted lines); the role of miniature defects on the electrochemical behavior becomes obvious. Firstly, it can be seen that unlike the macroscale measurements, the local potentiodynamic polarization curves on DLC are nearly identical to one another, showing the same current evolution regardless of the underlying interlayer material. Therefore, it can be postulated that the prominent potential domain established at an $i_{\text {plat }}$ of ca. $3.5 \mathrm{E}-8 \mathrm{~A} / \mathrm{cm}^{2}$ between ca. $-100 \mathrm{mV}$ to $150 \mathrm{mV}$, (evidenced by a plateau) can be attributed to the chemical stability of the DLC itself. After which, the gradual increase in current may indeed be attributed to the oxidation/dissolution of $\mathrm{C}$ within the DLC. The main difference between the macroscale and local polarization curves is found for the Ti/Co/DLC coated sample. Comparison between these two current evolution curves evidently demonstrates how the electrochemical measurements on a coated sample are highly dependent on the size of the characterized area. The measured current can show completely different behavior in the event that a coating defect is either included or excluded in the exposed working area. Therefore, care should be taken when interpreting the macroscopic electrochemical behavior of a coated surface. Since a potentiodynamic polarization curve displays a sum of the currents generated by all the reactions occurring at the coating surface, interlayer/interfaces, as well as the substrate, distinguishing the origin of each contribution is not always straightforward.

To become even more predictive and formulate corrosion mechanisms of complex multimaterial interfaces, a methodology for separating the current contributions and related 
corrosion susceptibility of the coating, interlayer and substrate is proposed. The experimental characterization combines: i) angled ion beam polishing generating a wedge to expose the buried interlayer, ii) characterization of the chemical composition of the actual deposited interlayer/interfaces by AES, and iii) specific local electrochemical characterization of each new interlayer material.

\subsection{Composition characterization of the interlayer and interfaces by AES}

After ion beam polishing of the samples, the chemical composition of the wedge-milled interlayers could be determined with the multipoint-linescan AES approach described in section 2.3 . For visualization purposes, Fig. 5 shows a SEM image of the wedge-milled Ti/Si/DLC sample used for AES and microcapillary electrochemical characterization. The AES data of this sample will be used as an example to demonstrate the analysis performed to separate the AES spectra into their respective compounds and elements.

Fig. 6a shows the stacked C(KLL) spectra, plotted as function of the kinetic energy (KE), relating to a sequence of the measurement points across the $\mathrm{Ti} / \mathrm{Si} / \mathrm{DLC}$ wedged interlayer. It can be seen that the $\mathrm{C}(\mathrm{KLL})$ spectrum of the carbon detected at the Ti/Si interface (at and around the $8^{\text {th }}$ spectrum from the bottom, in bold red) has a different shape than the spectrum obtained in the DLC (at and around $18^{\text {th }}$ spectrum, in bold blue). These two types of specific C(KLL) spectra are presented separately in Fig. 6b for clarification. The spectrum obtained on the DLC has the typical appearance of $\mathrm{C}-\mathrm{C}$ bonds found in DLC; with a peak maximum at $265 \mathrm{eV}$, and to the left a linear decreasing tail to $254 \mathrm{eV}$ and then a further signal intensity decrease to ca. $248 \mathrm{eV}$. This spectra shape is analogous to a reference AES spectrum published by Hauert et al. [31]. The spectrum obtained at the Ti/Si interface location displays a main sharper peak at $270 \mathrm{eV}$ and a much smaller peak at $260 \mathrm{eV}$, analogously to a reference measurement on $\mathrm{SiC}$ [31]. Carbides generally have very similar C(KLL) peak shapes, a 
maximum around $270 \mathrm{eV}$ and quickly decreasing tails, with the non-carbon component sometimes only slightly influencing the spectrum. At this point, the different peak shape can therefore be assigned to carbon in carbidic form (the type of carbide becomes obvious once the Ti and Si spectra are analyzed). All the C(KLL) spectra have then been separated into these two reference contributions ( $\mathrm{C}$ as DLC, and $\mathrm{C}$ as carbide at the Ti/Si interface) by LLSF, in order to produce the at\% composition curve of $\mathrm{C}$, as can be seen in Fig. 7a. This AES data analysis also revealed a certain contribution of $\mathrm{C}$ in carbidic form at the $\mathrm{Si} / \mathrm{DLC}$ interface as well.

Similarly to the C(KLL) spectra, the $\operatorname{Si}(\mathrm{LMM})$ spectra were analyzed in a stack plot and separated into different compounds by LLSF. The spectra from measurement points in the Si interlayer and at the Si/DLC interface were used for spectral fitting and are displayed in Fig. 6c. The peak shape of the spectrum from the interlayer can be assigned to pure $\mathrm{Si}$, with its pronounced peak at $89 \mathrm{eV}$. The spectrum from the Si/DLC interface (in red) can be assigned to $\mathrm{Si}$ as $\mathrm{SiC}$, with its broad peak at a lower $\mathrm{KE}$ of $86 \mathrm{eV}$, analogously to the $\mathrm{Si}(\mathrm{LMM})$ reference spectra published by R. Kosiba et al. [32] and Hauert et al. [31]. Therefore with agreement between both $\mathrm{C}(\mathrm{KLL})$ and $\mathrm{Si}(\mathrm{LMM})$ spectral fittings, this interface can indeed be assigned to $\mathrm{SiC}$. This is also expected since it was previously measured that when depositing DLC onto $\mathrm{Si}$, a SiC is formed at this interface [31].

Whereas the presence of $\mathrm{SiC}$ at the $\mathrm{Si} / \mathrm{DLC}$ interface could unambiguously be resolved, the presence of $\mathrm{SiC}$ at the $\mathrm{Ti} / \mathrm{Si}$ interface could not be detected, nor any other altered $\mathrm{Si}$ peak shape (such as the presence of TiSi). Since the LLSF analysis did not reveal a SiC at the Ti/Si interface, this indicates that the $\mathrm{C}$ at that interface can rather be assigned to $\mathrm{TiC}$ or $\mathrm{TiSiC}$ based on the analysis of the $\mathrm{C}(\mathrm{KLL})$ peak. This experimental observation makes sense, as TiC is the more energetically favorable carbide, having a standard Gibbs energy of formation 
$\left(\Delta \mathrm{Gf}^{\circ}\right)$ of $-43.2 \mathrm{kcal} / \mathrm{mol}$ at $25^{\circ} \mathrm{C}$, as opposed to $-15.0 \mathrm{kcal} / \mathrm{mol}$ for $\mathrm{SiC}$ [33]. The favored $\mathrm{TiC}$ formation would hence produce a much higher intensity in the AES spectrum at the Ti/Si interface. Although the presence of TiSi at the Ti/Si interface is also expected, kinetic energy separation of a TiSi peak from the pure Si signal may be below the resolution of the performed AES measurements.

$\mathrm{Ti}(\mathrm{LMM})$ spectra were separated in peaks of pure $\mathrm{Ti}$ in the substrate, and $\mathrm{Ti}$ at the $\mathrm{Ti} / \mathrm{Si}$ interface (in red), as shown in Fig. 6d. A different chemical state of Ti at the interface compared to the one of pure Ti in the substrate could be resolved, as seen in Fig. 7a. However assigning the energy shifts and altered peak shapes to a specific chemical component is difficult, as it may be TiC, TiSi, or TiSiC and only few AES reference data exist for this system. The main difference between the spectra of Fig. $6 \mathrm{~d}$ is in the tail intensities at kinetic energies below the highest peak at $382 \mathrm{eV}$ (note the peak intensity is normalized, resulting in some noise), as well as a slight offset between the right shoulder peaks at ca. $386 \mathrm{eV}$. Comparing these measurements to reference spectra of $\mathrm{Ti}$, TiC and $\mathrm{TiSi}$ found in Maline et al. [34], both TiC and TiSi show reduced intensities at kinetic energies below the $382 \mathrm{eV}$ peak, compared to pure $\mathrm{Ti}$, whereas only $\mathrm{TiC}$ shows a slight shift of the right shoulder peak to 386 $\mathrm{eV}$. Therefore, it is suggested that a larger part of the interface state of the Ti Auger signal originates from the presence of $\mathrm{TiC}$ at this interface. This conclusion is also supported by the fact that the presence of TiSi could not be resolved on the Si(LMM) peak.

The $\mathrm{TiC}$ at the $\mathrm{Ti} / \mathrm{Si}$ interface likely originated during the deposition process. As the PACVD chamber and sample holder contains DLC remnants from prior deposition processes, carbon can be sputtered from the sample holder and interact with the substrate during the Ar sputter cleaning step. The small amount of oxygen detected (as seen in Fig. 7a) can on the other hand 
mainly be assigned to oxygen recontamination during the long AES measurement, since oxygen is also detected on the pure Ti substrate.

The AES spectra of the other wedge-milled samples were analyzed in a similar manner to that of the Ti/Si/DLC example, and their at\% composition curves are presented in Fig. 7b-d.

Observing the profile of the Ti/Cr/DLC sample in Fig. 7b, it can be seen that the Cr interlayer is in fact not pure $\mathrm{Cr}$, but also contains ca. 20 at $\% \mathrm{C}$ as carbide throughout the interlayer with a slight increase at the interfaces. Although the $\mathrm{C}(\mathrm{KLL})$ spectra of carbides are very similar in shape, there is a feature in the $\mathrm{C}(\mathrm{KLL})$ chromium carbide $(\mathrm{Cr}-\mathrm{C})$ spectrum which makes it identifiable from $\mathrm{TiC}$ (assigned at the $\mathrm{Ti} / \mathrm{Si}$ interface), a slight shoulder to the right of the main peak at $275 \mathrm{eV}$ [25], as seen in Fig. 8. Therefore, this carbide could be assigned to $\mathrm{Cr}-\mathrm{C}$ chemical bonds. $\mathrm{Cr}-\mathrm{C}$ is one of the most energetically favored carbides, and can form spontaneously even at room temperature; at $25^{\circ} \mathrm{C}$, the $\Delta \mathrm{Gf}^{\circ}$ is $-22.7 \mathrm{kcal} / \mathrm{mol}$ for $\mathrm{Cr}_{3} \mathrm{C}_{2},-44.6$ $\mathrm{kcal} / \mathrm{mol}$ for $\mathrm{Cr}_{7} \mathrm{Cr}_{3}$, and $-96.9 \mathrm{kcal} / \mathrm{mol}$ for $\mathrm{Cr}_{23} \mathrm{C}_{6}$ [33]. As $\mathrm{Cr}$ has a very high tendency to bond with carbon, it may be that the $\mathrm{Cr}$ in the thin interlayer reacted with residual $\mathrm{C}$ in the chamber during deposition. The Ti/Cr interface likely contains a mixture of both favorable $\mathrm{TiC}$ and $\mathrm{Cr}-\mathrm{C}$ so that their contributions are not easily separated. The at $\%$ composition curves of the wedge-milled Ti/Co/DLC model sample (active corroding interlayer) is shown in Fig. 7c. The deposited interlayer is mainly pure Co with a slight carbide contribution towards the interfaces, determined by analyzing and splitting the different components in the C(KLL) spectra. From a measurement point at the Ti/Co interface, splitting of the C(KLL) spectra revealed a carbide contribution at this interface, as well as at the Co/DLC interface. The Ti(LMM) spectra could also be split and assigned to TiC. At the Co/DLC interface, the Co(LMM) spectra could not be clearly split or obviously assigned to a Co carbide (Co-C). The formation of Co-C is rather unfavorable, having a $\Delta \mathrm{Gf}^{\circ}$ of $+9.0 \mathrm{kcal} / \mathrm{mol}$ for $\mathrm{Co}_{3} \mathrm{C}$ at $25^{\circ} \mathrm{C}$ [35], so that the bonds between $\mathrm{Co}$ and $\mathrm{C}$ are rather weak and do not strongly alter the 
electron configuration of the Co. Some authors also reported the catalytic formation of a graphite layer during the initial stages of DLC deposition on Co [36,37], so this may also contribute to the $\mathrm{C}$ signal at the Co/DLC interface. . The AES analysis of the Si-DLC interlayer is shown in Fig. 7d and it is composed of ca. 30\% $\mathrm{Si}$ as $\mathrm{SiC}$, and 70\% C as carbide, consistent with previously published XPS depth profiling data of the same interlayer [38].

The AES chemical binding and surface composition characterization of the different wedged interfaces revealed numerous new materials with unknown reactivity in aggressive environments. These deposited interlayers including various carbide phases (shown to have an amorphous structure in previous work [39]) may have different electrochemical reactivity and corrosion resistance compared to that of, for example, pure metals or bulk carbide analogs that are anyway difficult to synthesize. Hence, direct local electrochemical characterization of the interlayer with its new interfaces with the microcapillary technique is of great interest and is presented in the next section as a third part of the characterization methodology.

\subsection{Interlayer electrochemical reactivity investigated by potentiodynamic polarization}

Since the local-electrochemical measurements allow for more representative characterization of the intrinsic electrochemical response of DLC in the absence of coating defects, the coating specific anodic polarization curves recorded for the DLC in Fig. 9a-d demonstrate that the "defect free" $2 \mu \mathrm{m}$ DLC coating is somewhat conductive, evidenced by a measurable local current at an $\mathrm{i}_{\text {plat }}$ of $3.5 \mathrm{E}-8 \mathrm{~A} / \mathrm{cm}^{2}$. The electrical properties of DLC can vary from that of a semiconductor, to that of a wide bandgap insulator depending on the deposition conditions [40]. At a deposition self-bias of $-600 \mathrm{~V}$ the specific resistivity of the DLC coatings, at room temperature, was previously measured to be $0.5 \mathrm{E}+5 \Omega \cdot \mathrm{m}$ [41], this is approximately in the resistivity range of gallium arsenide [42]. For all the coated samples with different interlayers considered, the local electrochemical potentiodynamic polarization measurements on the DLC 
showed reproducible, nearly identical, and relatively high current densities. The $\mathrm{E}_{\text {corr }}$ of the DLC is consistently ca. $-170 \mathrm{mV}$, followed by a stable $\mathrm{i}_{\text {plat }}$ at $3.5 \mathrm{E}-8 \mathrm{~A} / \mathrm{cm}^{2}$ regardless of the underlying interlayer, indicating that the electrochemical properties are controlled by the DLC.

The different local-electrochemical potentiodynamic polarization investigation of the wedgemilled interlayers are also presented in Fig. 9, along with the electrochemical response of the Ti substrate and DLC measured on each coated sample (already discussed above). The main electrochemical parameters $\left(\mathrm{i}_{\text {corr }}, \mathrm{i}_{\text {plat. }}\right.$, and $\left.\mathrm{E}_{\text {corr }}\right)$ obtained from the polarization curves are summarized in Table 2 , along with their standard deviations $(\sigma)$. In this study, the term $i_{\text {plat }}$ has been generally defined to refer to the plateaued region of the polarization curve representing either an inert surface (DLC) or a passivated surface (e.g. Ti). Except for the cobalt interlayer case (showing pseudo-passive behavior), the determined $i_{\text {corr }}$ values are related to passive film growth rates in the absence of an obvious plateau region (as in the polarization curves of $\mathrm{Si}$ ). The target material used for the magnetron sputtering process of the corresponding interlayer was also characterized by means of the microcapillary technique (specific current evolution represented by dotted lines), so that the electrochemical behavior of the bulk material could be compared to the one of the deposited interlayer.

\begin{tabular}{|c|c|c|c|c|}
\hline $\begin{array}{l}\text { Table 2: Main } \\
\text { electrochemical } \\
\text { parameters, with } \\
\text { corresponding } \\
\text { standard devia- } \\
\text { tions }(\sigma), \text { ob- } \\
\text { tained from the } \\
\text { polarization } \\
\text { measurements of }\end{array}$ & $\begin{array}{c}\mathbf{i}_{\text {corr }} \text { or } \mathbf{i}_{\text {plat }} \\
\left(\mathbf{A} / \mathbf{c m}^{2}\right)\end{array}$ & $\begin{array}{c}\sigma(\mathbf{i}) \\
\left(\mathrm{A} / \mathrm{cm}^{2}\right)\end{array}$ & $\begin{array}{l}\mathbf{E}_{\text {corr }} \\
(\mathbf{m V})\end{array}$ & $\begin{array}{c}\sigma \\
\left(E_{\text {corr }}\right) \\
(\mathbf{m V})\end{array}$ \\
\hline
\end{tabular}

Fig. 9. Material

\begin{tabular}{c|cccc} 
DLC & $3.5 \mathrm{E}-8$ & $5 \mathrm{E}-9$ & -170 & 10 \\
$\mathrm{Ti}$ & $1 \mathrm{E}-7$ & $3 \mathrm{E}-9$ & -400 & 30
\end{tabular}




\begin{tabular}{c|cccc} 
Co interlayer & $7.3 \mathrm{E}-6$ & $1 \mathrm{E}-6$ & -380 & 15 \\
Cr interlayer & $6.5 \mathrm{E}-8$ & $9 \mathrm{E}-9$ & -220 & 36 \\
Si interlayer & $2.7 \mathrm{E}-8$ & $1 \mathrm{E}-9$ & -660 & 43 \\
Si-DLC interlay- & $2.7 \mathrm{E}-8$ & $5 \mathrm{E}-9$ & -185 & 20 \\
er & & & &
\end{tabular}

Wedge-milling of the coated samples makes the interlayers and their new interface materials easily accessible to the microcapillary for electrochemical characterization, due to the lateral widening. For example, a residual ring left after microcapillary characterization performed with a $30 \mu \mathrm{m}$ diameter capillary is shown on the Si area of the Ti/Si/DLC wedge-milled sample, validating the correct positioning of the capillary (Fig. 5). The ring is composed of residual HyClone ${ }^{\circledR}$ WTF and Si corrosion products (as characterized by SEM/EDX).

The first case presented is the local-potentiodynamic polarization behavior of the model Ti/Co/DLC wedge-milled sample, Fig. 9a. The substrate shows typical electrochemical behavior for Ti with a low $\mathrm{E}_{\mathrm{corr}}$ at $-400 \mathrm{mV}$ (characteristic of reactive metals), followed by a passive domain (in the $1 \mathrm{E}-7 \mathrm{~A} / \mathrm{cm}^{2}$ range) with a further increase of the passivation current starting at $100 \mathrm{mV}$, related to polarization induced oxide growth. As already mentioned, Co is known to be very active within the neutral $\mathrm{pH}$ domain so that a stark contrast between the $\mathrm{Ti}$ and Co polarization curves is expected, and indeed is observed. It can be seen that the current density evolution of the Co interlayer exhibits similar features compared to that of the bulk Co curve; a brief "pseudo" passivation (high measured current density) domain from ca. -380 $\mathrm{mV}$, until a pitting potential of $\mathrm{ca}-10 \mathrm{mV}$ is reached, where the current rapidly increases to very high values due to active dissolution. One difference is however that the bulk Co exhibits even higher current densities of ca. $1 \mathrm{E}-4 \mathrm{~A} / \mathrm{cm}^{2}$, approximately one order of magnitude higher than the Co interlayer. Hence, even when a pure and active interlayer is present, its electrochemical reactivity in complex electrolytes such as Hyclone ${ }^{\circledR}$ WTF can still vary 
slightly from the bulk material. Nevertheless, comparison with the bulk behavior shows that the microcapillary technique was able to measure the active dissolution behavior of a $60 \mathrm{~nm}$ thick deposited Co interlayer separately from the substrate and coating response, and the method could now be applied to the more practice-relevant interlayer materials ( $\mathrm{Si}, \mathrm{Cr}-\mathrm{C}$, and Si-DLC).

The local electrochemical potentiodynamic polarization measurement of the $\mathrm{Cr}-\mathrm{C}$ interlayer (as characterized by AES in Fig. 7b) is shown in Fig. 9b, together with reference measurements on DLC and the bulk Cr target. It can be seen from the current density evolution that the $\mathrm{Cr}-\mathrm{C}$ interlayer behaves neither as pure $\mathrm{Cr}$, nor as DLC, but rather somewhere in between. Initially, the measured currents resemble the behavior of the DLC, having a similar prominent passive plateau domain. This can likely be attributed to oxidation hindering induced by the $\mathrm{C}$ in the interlayer, resulting in analogous behavior as the $\mathrm{C}$ in the DLC. The current then increases exponentially between ca. $170-600 \mathrm{mV}$ to ca. $1 \mathrm{E}-4 \mathrm{~A} / \mathrm{cm}^{2}$, after which the curve overlaps the pure $\mathrm{Cr}$ curve above $600 \mathrm{mV}$. The current increase in the intermediate potential domain $(170-600 \mathrm{mV})$ can be attributed to transpassive dissolution of Cr-oxide, analogously to the mechanism for a pure $\mathrm{Cr}$ surface.. The latter portion of the $\mathrm{Cr}-\mathrm{C}$ interlayer curve (above $600 \mathrm{mV}$ ) is then fully dominated by Cr-oxide transpassive dissolution. This example demonstrates how the local-electrochemical measurements can be utilized to more accurately assign the contributions of the current response to different surface reactions. The influence of the incorporation of $\mathrm{C}$ within the interlayer (in this case ca. 20 at\%) could be identified as an improvement in the chemical stability, compared to the higher oxidation currents observed for pure $\mathrm{Cr}$. Hence the $\mathrm{Cr}$-C interlayer shows good chemical stability, given the potential is maintained at the $\mathrm{E}_{\text {corr }}$, as demonstrated in the OCP measurement of the next section, or below the onset of active currents (between ca. $-200 \mathrm{mV}$ to $400 \mathrm{mV}$ ). However if 
higher potentials are expected to be applied, such as in some sensor applications, the electrochemical stability of this particular $\mathrm{Cr}-\mathrm{C}$ interlayer may not be suitable.

Regarding the Si interlayer, the local-electrochemical characterization of the wedge-milled Ti/Si/DLC sample is presented in Fig. 9c, along with the one of the Si target used for the magnetron sputtering deposition. It can be seen that the $\mathrm{E}_{\mathrm{corr}}$ of the sputtered Si interlayer, and the bulk Si differ. The polarization curve of the Si interlayer material shows a relatively active (low) $\mathrm{E}_{\text {corr }}$ of ca. $-660 \mathrm{mV}$ compared to the curves of the bulk Si and the Ti substrate, indicating it has the viability to corrode if coupled to the Ti. Although with increasing anodic potential the current density remains low, not exceeding ca. $2 \mathrm{E}-6 \mathrm{~A} / \mathrm{cm}^{2}$. The local electrochemical polarization curve of the bulk Si demonstrates similar current densities, but with a much higher (nobler) $\mathrm{E}_{\mathrm{corr}}$ of ca. $-340 \mathrm{mV}$. The low currents of the potentiodynamic polarization curve may indicate a stable oxide on the interlayer and bulk $\mathrm{Si}$, however from previous work [14], it was demonstrated that Si oxide is easily stabilized by anodic polarization. For this reason, OCP evolution monitoring, presented in the next section, combined with the potentiodynamic polarization information serves as a better diagnostic for assessing the surface oxide stability and corrosion susceptibility of Si.

Concerning the Ti/Si-DLC/DLC sample, since the Si-DLC is deposited from TMS gas, a bulk reference could not be characterized. The Si-DLC deposited interlayer exhibits somewhat similar behavior to that of DLC, as seen in Fig. 9d. This electrochemical current response is expected, as the material is essentially DLC doped with some Si. However, the chemical stability (plateaued current density up to ca. $100 \mathrm{mV}$ ) is not as good as the DLC, and stronger oxidation currents are measured at higher applied potentials.

In comparison to the $\mathrm{E}_{\text {corr }}$ 's of the interlayer materials presented in Fig. 9a-d, DLC always displays the noblest (most positive) $\mathrm{E}_{\text {corr. }}$ This means that in reference to the underlying 
materials, DLC could theoretically act as a cathode given its semi-conducting nature. Hence, if electrolyte penetrates the coating through a defect and reaches the interface material, galvanic coupling may occur at the interface of the noble coating and less noble underlying material. This phenomenon can accelerate the degradation process of the underlying material. Such a mechanism has also been used to describe the delamination in $\mathrm{NaCl}$ solution of conducting TiN coatings deposited on stainless steel, due to local galvanic coupling of the steel with the more noble coating [12].

\subsection{Long-term interlayer stability assessment at OCP}

Complimentary to the local-electrochemical polarization measurements presented in the previous section, the OCP evolution of the wedge-milled interlayers was also characterized by means of the microcapillary technique over 24 hours. This characterization avoids any anodic polarization oxidation effects and assesses the corrosive susceptibility at longer, freely corroding conditions. Fig. 10a shows a compilation of the OCP evolution measurements obtained for the Si-DLC, Cr-C and Si based interlayers, along with the OCP evolution of the

Ti substrate for reference. It can be seen that the OCP evolution of the $\mathrm{Cr}-\mathrm{C}$ interlayer stays at a consistently high and constant value of ca. $-250 \mathrm{mV}$. From the $\mathrm{C}-\mathrm{H}_{2} \mathrm{O}$ and $\mathrm{Cr}-\mathrm{H}_{2} \mathrm{O}$ thermodynamic considerations (Pourbaix) at $\mathrm{pH} 7.4, \mathrm{Cr}_{2} \mathrm{O}_{3}$ and $\mathrm{C}$ are stable in this potential domain, indicating passivity of the interlayer. The Si-DLC interlayer also presents a consistently high OCP evolution around ca. $-200 \mathrm{mV}$. The long-term OCP evolution of the Si interlayer, and bulk Si, however indicates very different stability behavior. The $24 \mathrm{~h}$ OCP measurement shows decreasing potentials, indicating progressive destabilization of the surface. It can be seen that the Si interlayer exhibits a continuous drop in potential, with transients, from ca. $-720 \mathrm{mV}$ to ca. $-770 \mathrm{mV}$, better evidenced on an enlarged axis in Fig. $10 \mathrm{~b}$ (on the right y-axis). It is important to consider that in the presence of $\mathrm{H}_{2} \mathrm{O}, \mathrm{SiO}_{2}$ is stable above an equilibrium potential of ca. $-1000 \mathrm{mV}$ (vs. $\mathrm{Ag} / \mathrm{AgCl} \mathrm{RE}$ ) at ca. $\mathrm{pH} 7.4$ (from the Si- 
$\mathrm{H}_{2} \mathrm{O}$ thermodynamic system [43]), so that the measured OCP values cannot yet by interpreted as representing a completely active corroding surface. The influence of proteins and additional species (phosphate, chloride, etc) in HyClone ${ }^{\circledR}$ WTF can however narrow the Sioxide stability domain, so that a potential evolution from ca. -720 down to $-770 \mathrm{mV}$ can be indicative of $\mathrm{SiO}_{2}$ dissolution. Phosphorous species within Hyclone ${ }^{\circledR}$ WTF can complex to form soluble phosphorous-silicon complexes, as proposed by W. van Gelder [44] and by E.Ilic et al. [14], resulting in further corrosion of the Si. To support this hypothesis of Si activation, the OCP evolution of bulk Si (from the sputter target) was characterized under the same microcapillary measurement conditions and is also shown in Fig. 10b (on the left yaxis). The OCP evolution of the bulk Si also experiences a continuous drop in potential, even more pronounced from ca. $-400 \mathrm{mV}$ to ca. $-600 \mathrm{mV}$, indicating that the surface is also affected by passive oxide dissolution in HyClone ${ }^{\circledR}$ WTF. The situation is however not as detrimental as in the case of the deposited Si interlayer because the higher initial OCP of the bulk Si indicates better passivation, and even at the final potential of $-600 \mathrm{mV}$, the surface is still not in active dissolution conditions. For this reason, monitoring the local OCP evolution and over an extended period can serve as a good diagnostic for corrosion initiation susceptibility and growth, depending on the material of interest.

Fig. 11b shows the detrimental state of a wedge-milled Si interlayer after being immersed at freely corroding conditions (OCP) over an extended period. The initial state of the wedgemilled Ti/Si/DLC sample is shown in Fig. 11a (of the similar type as the one presented in Fig. 5). Initially, the lateral width of the wedge-milled Si interlayer is $60 \mu \mathrm{m}$ (the deposited thickness is $60 \mathrm{~nm})$. After immersing the sample in HyClone ${ }^{\circledR} \mathrm{WTF}$ at room temperature for ca. 1.5 years, it can be seen that the interlayer and adjacent DLC coating is degraded and the Si interlayer has retracted (corroded) towards the DLC. There is no longer a smooth transition boundary at the Si/DLC interface, but rather a discontinuous delaminating DLC front can be 
seen. Delamination spots are also visible in the DLC coating, likely due to local defects which were initially present in this thinned region of the wedge-milled DLC. These corrosion attacks are analogous to the ones responsible for the failure case of a $\mathrm{Ti}_{6} \mathrm{Al}_{4} \mathrm{~V} / \mathrm{Si} / \mathrm{DLC}$ implant; after 4 years in the body, FIB cuts into the retrieved implant revealed that the $60 \mathrm{~nm}$ think $\mathrm{Si}$ interlayer was missing at some locations [13,14].

With the proposed methodology, the local-electrochemical measurements show that the $\mathrm{Si}$ interlayer corrosion susceptibility is responsible for the failure in the Ti/Si/DLC sample, as was confirmed by the long-term immersion experiment. On the other hand, $\mathrm{Cr}-\mathrm{C}$ and $\mathrm{Si}-\mathrm{DLC}$ are much more corrosion resistant interlayers.

In addition, the wedge-milling approach also allows for characterization of the different materials on the same-deposited sample. When solely utilizing macro-electrochemistry, the bare substrate, or the interlayer before DLC deposition, is usually characterized first and used as a reference. This reference is then compared with the surface characterization of each deposited layer (substrate/interlayer and substrate/interlayer/coating). For this, different samples are prepared in different deposition processes.

Across different deposition processes, chamber conditions may vary resulting in slightly different interface materials that have to be considered. The aim of the paper is not to obtain perfect interlayer materials, but to address with high laterally resolved methods the influence of small amounts of impurities on the corrosion susceptibility of these nm-thick new materials. 


\section{Conclusions}

This study presents a methodology for characterizing the chemical state composition and the corrosion susceptibility of buried interlayers/interfaces by combining; ionic wedge-milling of coated samples, compositional characterization of the interlayer/interfaces by AES, and utilization of a microcapillary technique for local-electrochemical assessment of the interlayer stability. The following can be concluded from the experimental observations:

- Macro-electrochemical potentiodynamic polarization measurements of DLC coated sample surfaces vary considerably depending on the underlying material and on the extent/distribution of coating defects. Local-electrochemical measurements (four orders of magnitude smaller exposed areas) are more representative of the intrinsic behavior of the coating, such as DLC, showing nearly identical electrochemical reactivity regardless of the underlying material.

- Ionic wedge-milling of a coated sample (substrate/interlayer/coating) allowed for exposure of the buried interlayer and its corresponding interfaces. An interlayer could be exposed laterally over 1000 times compared to its deposited thickness to make subsequent composition and electrochemical characterization much more accurate.

- The chemical composition of the interlayers and interfaces could be resolved, at least semi-quantitatively, with AES by collecting spectra from a multipoint-linescan across the wedge-milled samples. Carbides could be resolved at the interfaces by performing detailed chemical binding identification with the Auger lines and by assigning peak shapes to reference spectra from known compounds. The observed susceptibility to carbide formation is in line with the thermodynamic formation energy; Co is present as pure metal, whereas a $\mathrm{Cr}$ interlayer contains the most carbon. 
- Local microcapillary electrochemical measurements allowed for characterization of the corrosion susceptibility of the wedge-milled interlayers, in reference to the substrate and DLC coating electrochemical response, characterized on the same deposited sample. Crcarbide and Si-DLC (deposited from TMS) showed to be corrosion resistant interlayer materials in both OCP and potentiodynamic polarization experiments.

- A Si interlayer showed electrochemical instability over extended freely corroding (at OCP) conditions, analogous to a long-term immersion experiment and failed $\mathrm{Ti}_{6} \mathrm{Al}_{4} \mathrm{~V} / \mathrm{Si} / \mathrm{DLC}$ implant cases.

In general, the presented methodology based on laterally resolved techniques can be used in combination with macro-electrochemistry to obtain corrosion susceptibility information of any buried interlayer with unknown electrochemical characteristics, and to determine the intrinsic behavior of a coating and interlayer by excluding defects from the measured area. 


\section{Acknowledgements}

The authors would like to acknowledge the Swiss National Science Foundation (project number 200021_156085) for financially supporting this research. Thank you also to Martin Sauder and Ulrich Müller for operational training of polishing equipment and of the PACVD chamber. As well to Lars Jeurgens and Rowena Crockett from Empa for their helpful discussions. Thank you to Max Doebeli from ETH for the ERDA analysis. 


\section{References}

[1] R. Hauert, K. Thorwarth, G. Thorwarth, An overview on diamond-like carbon coatings in medical applications, Surf. Coatings Technol. 233 (2013) 119-130.

doi:10.1016/j.surfcoat.2013.04.015.

[2] S. V. Hainsworth, N.J. Uhure, Diamond like carbon coatings for tribology: production techniques, characterisation methods and applications, Int. Mater. Rev. 52 (2007) 153174. doi:10.1179/174328007X160272.

[3] K.A. Pischow, L. Eriksson, E. Harju, A.S. Korhonen, E.O. Ristolainen, The influence of titanium interlayers on the adhesion of PVD TiN coatings on oxidized stainless steel substrates, Surf. Coatings Technol. 58 (1993) 163-172. doi:10.1016/02578972(93)90003-7.

[4] W. Tillmann, A. Fehr, D. Stangier, M. Dildrop, Influences of substrate pretreatments and $\mathrm{Ti} / \mathrm{Cr}$ interlayers on the adhesion and hardness of CrAlSiN and TiAlSiN films deposited on $\mathrm{Al} 2 \mathrm{O} 3$ and $\mathrm{ZrO} 2-8 \mathrm{Y} 2 \mathrm{O} 3$ thermal barrier coatings, Results Phys. 12 (2019) 2206-2212. doi:10.1016/j.rinp.2019.02.048.

[5] B. Rother, T. Lunow, G. Leonhardt, Interface strength of titanium nitride coatings on hardened high-speed steel, Surf. Coatings Technol. 71 (1995) 229-232.

doi:10.1016/0257-8972(94)02317-J.

[6] C.C. Chen, F.C.N. Hong, Interfacial studies for improving the adhesion of diamondlike carbon films on steel, Appl. Surf. Sci. 243 (2005) 296-303. doi:10.1016/j.apsusc.2004.09.085.

[7] Y. Xiang, Y. Liu, W. Cheng-biao, L. Xin-chun, Y. De-yang, Investigation on preparation and properties of thick DLC film in medium-frequency dual-magnetron sputtering, Vacuum. 80 (2005) 324-331. doi:10.1016/j.vacuum.2005.06.002.

[8] R. Maiti, R. Mills, Wear properties of diamond-like carbon coatings with silicon and chromium as adhesion layer using a high frequency reciprocating rig, J. Eng. Tribol. 231 (2017) 1605-1615. doi:10.1177/1350650117704788.

[9] L.F. Bonetti, G. Capote, L. V Santos, E.J. Corat, V.J. Trava-Airoldi, Adhesion studies of diamond-like carbon films deposited on Ti6Al4V substrate with a silicon interlayer, Thin Solid Films. 515 (2006) 375-379. doi:10.1016/j.tsf.2005.12.154.

[10] S. V Hattangady, M.J. Mantini, G.G. Fountain, R.A. Rudder, R.J. Markunas, The role of an ultrathin silicon interlayer at the SiO2-Ge interface, J. Appl. Phys. 71 (1992) 3842-3852. doi:10.1063/1.350874.

[11] A.E.J. Lim, T.Y. Liow, K.K. Chen, R.P.C. Tern, G.Q. Lo, Novel epitaxial silicon interlayer for junction engineering in aggressively-scaled germanium photodetectors, AIP Adv. 3 (2013) 1-6. doi:10.1063/1.4821118.

[12] I. Kucuk, C. Sarioglu, Pitting corrosion of TiN-coated stainless steel in $3 \% \mathrm{NaCl}$ 
solution, Mater. Technol. 49 (2015) 183-192. doi:10.17222/mit.2013.176.

[13] R. Hauert, C. V. Falub, G. Thorwarth, K. Thorwarth, C. Affolter, M. Stiefel, L.E. Podleska, G. Taeger, Retrospective lifetime estimation of failed and explanted diamond-like carbon coated hip joint balls, Acta Biomater. 8 (2012) 3170-3176. doi:10.1016/j.actbio.2012.04.016.

[14] E. Ilic, A. Pardo, R. Hauert, P. Schmutz, S. Mischler, Silicon Corrosion in Neutral Media: The Influence of Confined Geometries and Crevice Corrosion in Simulated Physiological Solutions, J. Electrochem. Soc. 166 (2019) C125-C133. doi:10.1149/2.0241906jes.

[15] R. Hauert, G. Thorwarth, U. Müller, M. Stiefel, C. V. Falub, K. Thorwarth, T.J. Joyce, Analysis of the in-vivo failure of the adhesive interlayer for a DLC coated articulating metatarsophalangeal joint, Diam. Relat. Mater. 25 (2012) 34-39. doi:10.1016/j.diamond.2012.02.001.

[16] P.D. Maguire, J.A. McLaughlin, T.I.T. Okpalugo, P. Lemoine, P. Papakonstantinou, E.T. McAdams, M. Needham, A.A. Ogwu, M. Ball, G.A. Abbas, Mechanical stability, corrosion performance and bioresponse of amorphous diamond-like carbon for medical stents and guidewires, Diam. Relat. Mater. 14 (2005) 1277-1288.

doi:10.1016/j.diamond.2004.12.023.

[17] L. Joska, J. Fojt, O. Mestek, L. Cvrcek, V. Brezina, The effect of a DLC coating adhesion layer on the corrosion behavior of titanium and the Ti6Al4V alloy for dental implants, Surf. Coatings Technol. 206 (2012) 4899-4906.

doi:10.1016/j.surfcoat.2012.05.089.

[18] M. Azzi, P. Amirault, M. Paquette, J.E. Klemberg-Sapieha, L. Martinu, Corrosion performance and mechanical stability of 316L/DLC coating system: Role of interlayers, Surf. Coatings Technol. 204 (2010) 3986-3994. doi:10.1016/j.surfcoat.2010.05.004.

[19] Y. Massiani, A. Medjahed, P. Gravier, J.P. Crousier, Effect of a titanium underlayer on the corrosion behaviour of physically vapour deposited titanium nitride films, Thin Solid Films. 217 (1992) 31-37. doi:10.1016/0040-6090(92)90602-8.

[20] H.A. Jehn, Improvement of the corrosion resistance of PVD hard coating-substrate systems, Surf. Coatings Technol. 125 (2000) 212-217. doi:10.1016/S02578972(99)00551-4.

[21] H.A. Jehn, P. Schaller, Corrosion of hard coatings. part 2-results of the study and coating properties, Galvanotechnik. 84 (1993) 3669-3675.

[22] B. Matthes, E. Broszeit, J. Aromaa, H. Ronkainen, S.P. Hannula, A. Leyland, A. Matthews, Corrosion performance of some titanium-based hard coatings, Surf. Coatings Technol. 49 (1991) 489-495. doi:10.1016/0257-8972(91)90105-6.

[23] H.A. Jehn, M.E. Baumgärtner, Corrosion studies with hard coating-substrate systems, Surf. Coatings Technol. 54/55 (1992) 108-114. doi:10.1016/S0257-8972(09)90036-6. 
[24] J. Robertson, Diamond-like amorphous carbon J., Mater. Sci. Eng. R. 216 (2010) 868871. doi:10.1063/1.369293.

[25] M.A. Smith, L.L. Levenson, Final-state effects in carbon Auger spectra of transitionmetal carbides, Phys. Rev. B. 16 (1977) 1365-1369.

[26] T. Suter, H. Böhni, The Microcell Technique, in: Anal. Methods Corros. Sci. Eng., 2006: pp. 649-696. doi:doi:10.1201/9781420028331.ch17.

[27] E. Deltombe, M. Pourbaix, Colbalt, in: M. Pourbaix (Ed.), Atlas Electrochem. Equilibria Aqueous Solut., 2nd ed., NACE, Houston, 1974: pp. 322-329.

[28] E. Deltombe, N. Zoubov, M. Pourbaix, Chromium, in: M. Pourbaix (Ed.), Atlas Electrochem. Equilibria Aqueous Solut., 2nd ed., NACE, Houston, 1974: pp. 256-271.

[29] J. V Muylder, Carbon, in: M. Pourbaix (Ed.), Atlas Electrochem. Equilibria Aqueous Solut., 2nd ed., NACE, Houston, 1974: pp. 449-457.

[30] L. Joska, J. Fojt, L. Cvrcek, V. Brezina, Properties of titanium-alloyed DLC layers for medical applications, Biomatter. 4 (2014) 1-7. doi:10.4161/biom.29505.

[31] R. Hauert, J. Patscheider, R. Zehringer, M. Tobler, Analysis of a-C:H superhard coatings by scanning Auger microscope and target factor analysis, Thin Solid Films. 206 (1991) 330-334. doi:10.1016/0040-6090(91)90445-4.

[32] R. Kosiba, J. Liday, G. Ecke, O. Ambacher, J. Breza, P. Vogrinčič, Quantitative Auger electron spectroscopy of SiC, Vacuum. 80 (2006) 990-995.

doi:10.1016/j.vacuum.2006.01.003.

[33] L. Pankratz, Thermodynamic properties of carbides, nitrides, and other selected substances, U. S. Dep. Inter. Bur. Mines. Bulletin 6 (1994).

[34] M. Maline, M. Ducarroir, F. Teyssandier, R. Hillel, R. Berjoan, F.J.J. Van Loo, W. Wakelkamp, Auger electron spectroscopy of compounds in the Si-Ti-C system, Surf. Sci. 286 (1993) 82-91. doi:10.1201/9780203741528-5.

[35] S.R. Shatynski, The thermochemistry of transition metal carbides, Oxid. Met. 13 (1979) 105-118. doi:10.1007/BF00611975.

[36] S.A. Catledge, R. Vaid, P. Diggins IV, J.J. Weimer, M. Koopman, Y.K. Vohra, Improved adhesion of ultra-hard carbon films on cobalt- chromium orthopaedic implant alloy, J. Mater. Sci. Mater. Med. 22 (2011) 307-316. doi:10.1007/s 10856-0104207-1.Improved.

[37] X. Chen, J. Narayan, Effect of the chemical nature of transition-metal substrates on chemical-vapor deposition of diamond, J. Appl. Phys. 74 (1993) 4168-4173. doi:10.1063/1.354420.

[38] A. Pardo, E. Ilic, K. Thorwarth, M. Stiefel, R. Hauert, Corrosion fatigue in DLC-coated articulating implants: an accelerated methodology to predict realistic interface lifetime, 
Sci. Technol. Adv. Mater. 20 (2019) 173-186. doi:10.1080/14686996.2019.1580483.

[39] C. V. Falub, U. Müller, G. Thorwarth, M. Parlinska-Wojtan, C. Voisard, R. Hauert, In vitro studies of the adhesion of diamond-like carbon thin films on CoCrMo biomedical implant alloy, Acta Mater. 59 (2011) 4678-4689. doi:10.1016/j.actamat.2011.04.014.

[40] A. Grill, Electrical and optical properties of diamond-like carbon, Thin Solid Films. $\underline{355 \text { (1999) 189-193. doi:10.1016/S0040-6090(99)00516-7. }}$

[41] L.J.C. Knoblauch-Meyer, Auswirkungen der Schichtstruktur von a-C : H Multilagen auf ihr tribologisches Verhalten (Doctoral dissertation), University of Zurich, 1999.

[42] The Editors of Encyclopaedia Britannica, Semiconductor, Encycl. Br. Inc. (2019). https://www.britannica.com/science/semiconductor (accessed July 17, 2019).

[43] J. Van Muylder, J. Besson, W. Kunz, M. Pourbaix, Silicon, in: M. Pourbaix (Ed.), Atlas Electrochem. Equilibria Aqueous Solut., 2nd ed., NACE, Houston, 1974: pp. 459-463.

[44] W. Van Gelder, V.E. Hauser, The Etching of Silicon Nitride in Phosphoric Acid with Silicon Dioxide as a Mask, J. Electrochem. Soc. 114 (1967) 869.

doi:10.1149/1.2426757. 


\section{$7 \quad$ Figure Captions}

Fig. 1: Schematic illustrating the corrosion mechanisms occurring at a substrate/DLC interface at miniature coating defects.

Fig. 2. Schematic of angled $\mathrm{Ar}^{+}$beam polishing of a DLC coated substrate with an interlayer. A wedge-like profile is milled into the sample, exposing the underlying materials.

Fig. 3. Schematic of the microcapillary technique for local electrochemical characterization. In this case, the exposed area (working eletrode, WE) is a wedge-milled Ti/interlayer/DLC area.

Fig. 4. Electrochemical potentiodynamic polarization curves of DLC coated samples performed with a macroscale cell $\left(0.2 \mathrm{~cm}^{2}\right.$ working area), solid lines, and a microcapillary (3.85E-5 $\mathrm{cm}^{2}$ working area) dashed lines. The electrolyte used was HyClone ${ }^{\circledR}$ WTF.

Fig. 5. SEM image of a wedge-milled Ti/Si/DLC sample after local electrochemical characterization with the microcapillary. The Si interlayer and its corresponding interfaces with Ti and DLC, have laterally exposed.

Fig. 6. AES spectra used to fit the at\% composition curves for the wedge milled Ti/Si/DLC sample in Fig. 7a. a) stack plot of the C(KLL) spectra. b) C(KLL) spectra measured in the DLC and at the Ti/Si interface. c) $\mathrm{Si}(\mathrm{LMM})$ spectra measured in the $\mathrm{Si}$ interlayer and at the $\mathrm{Si} / \mathrm{DLC}$ interface. d) $\mathrm{Ti}(\mathrm{LMM})$ spectra measured in Ti substrate and at the Ti/Si interface.

Fig. 7: AES at\% composition curves of the wedge-milled samples: a) Ti/Si/DLC, b) $\mathrm{Ti} / \mathrm{Cr} / \mathrm{DLC}, \mathrm{c}) \mathrm{Ti} / \mathrm{Co} / \mathrm{DLC}$ and d) Ti/Si-DLC/DLC. Carbides have been assigned by comparison to published reference spectra.

Fig. 8. Normalized AES C(KLL) spectra at the Cr/DLC interface compared to the spectra at a $\mathrm{Ti} / \mathrm{Si}$ interface (peak assigned to $\mathrm{TiC}$ ), the shoulder at $275 \mathrm{eV}$ is characteristic of $\mathrm{Cr}-\mathrm{C}$. The peaks have been slightly offset for comparison purposes.

Fig. 9. Local polarization measurements conducted with a microcapillary filled with HyClone ${ }^{\circledR}$ WTF as the electrolyte, on wedge-milled samples: a) Ti/Co/DLC, b) Ti/Cr/DLC, c) $\mathrm{Ti} / \mathrm{Si} / \mathrm{DLC}$, d) Ti/Si-DLC/DLC. The respective interlayer magnetron sputter targets were also characterized.

Fig. 10. Local OCP evolution measurements conducted with a microcapillary filled with HyClone ${ }^{\circledR}$ WTF as the electrolyte on: a) Si-DLC, Cr-C and Si interlayers, and Ti substrate. b) Comparison of the OCP evolution of bulk Si (on left y-axis) and of the Si interlayer (on right y-axis).

Fig. 11. a) SEM image of a newly wedge-milled Ti/Si/DLC sample before immersion in HyClone ${ }^{\circledR}$ WTF. b) SEM image of the same sample after immersion in HyClone ${ }^{\circledR}$ WTF for 1.5 years, showing retracted (corroded) Si interlayer and adjacent DLC delamination front. 


\section{Highlights}

- Characterization combining ionic polishing, Auger Electron Spectroscopy (AES) and local electrochemistry of interlayers/interfaces

- Chemical analysis at substrate/interlayer and interlayer/DLC interfaces by AES

- Microcapillary technique applied on interlayer for local-electrochemical reactivity assessment

- Chemical instability of Si interlayer in bovine-based wear test fluid demonstrated 


\section{corrosive media}

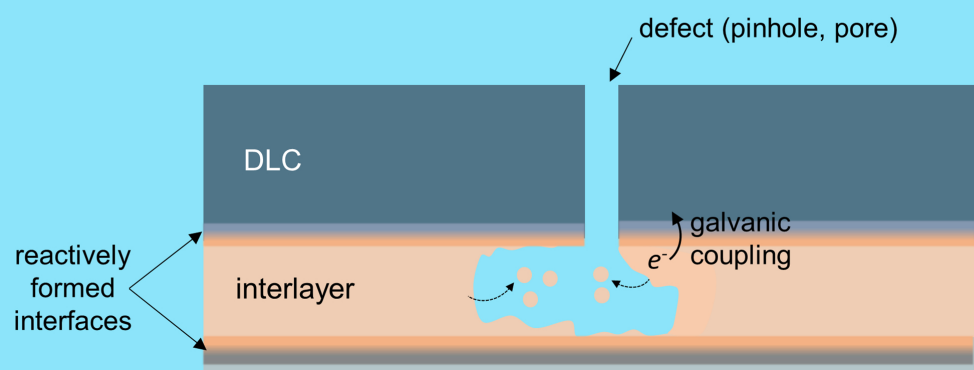

substrate

Figure 1 


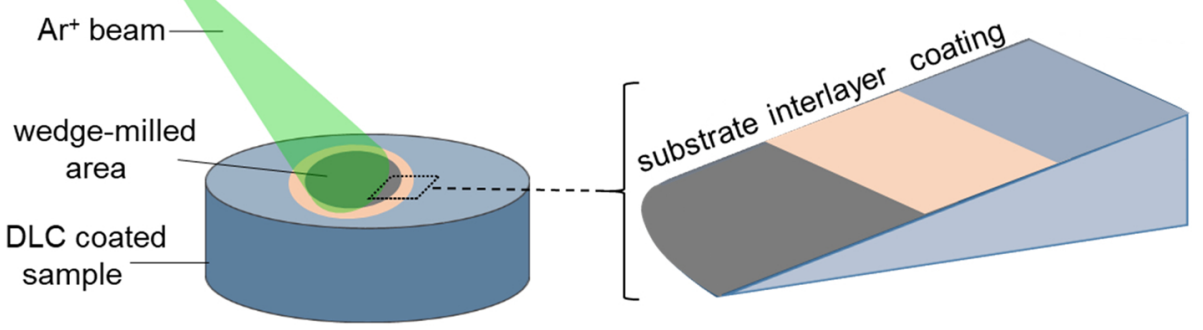

Figure 2 


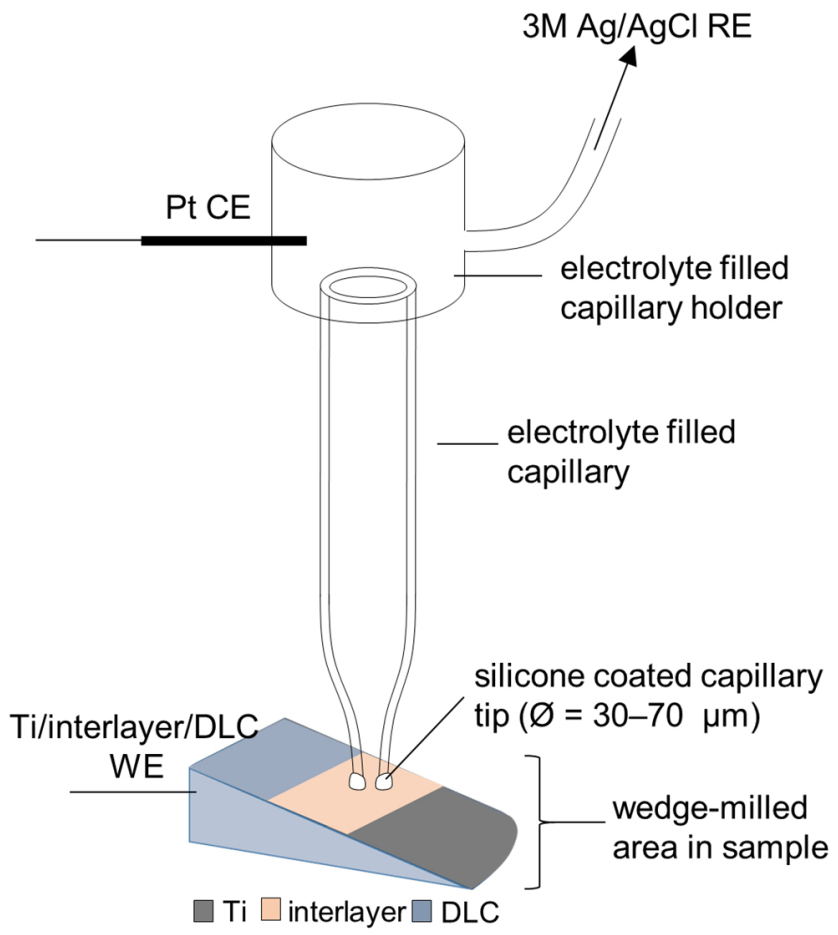

Figure 3 


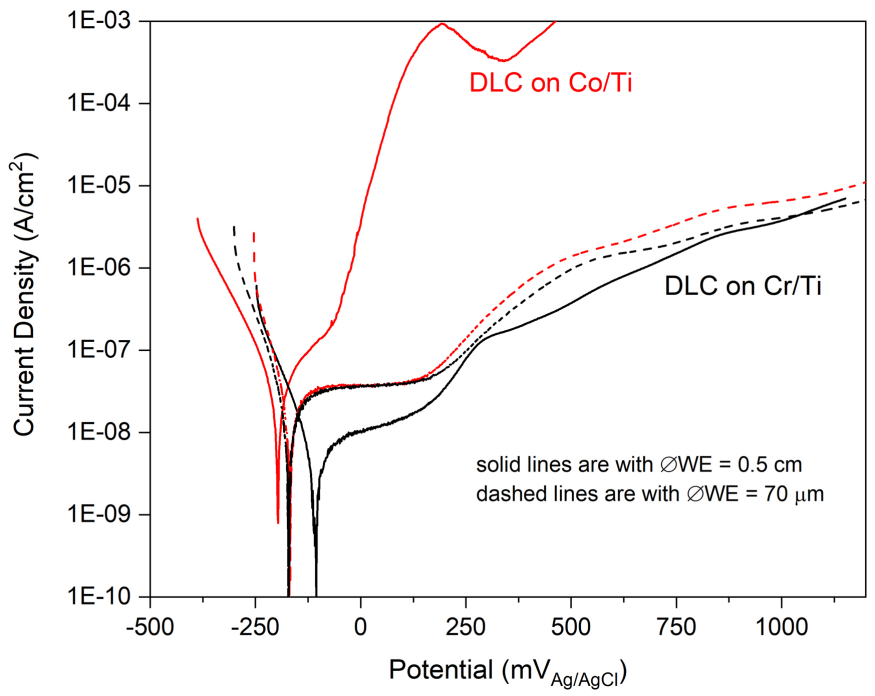

Figure 4 


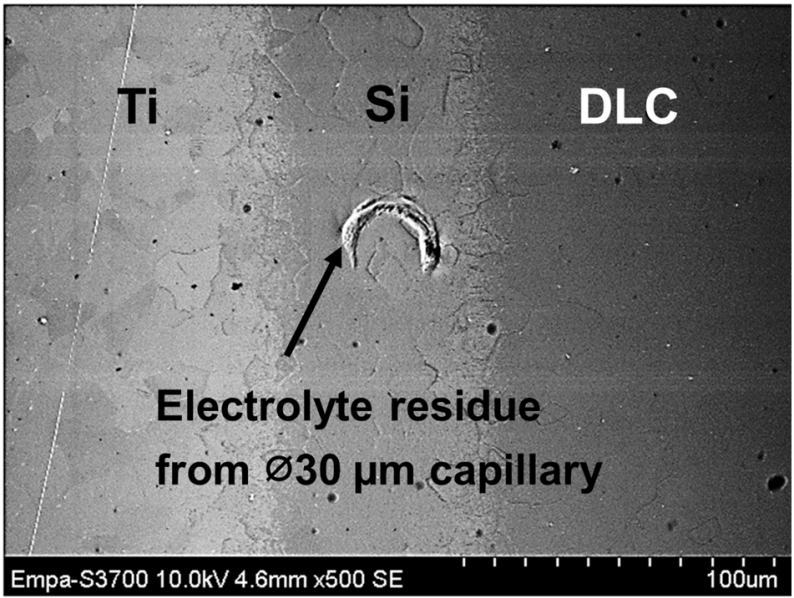

Figure 5 

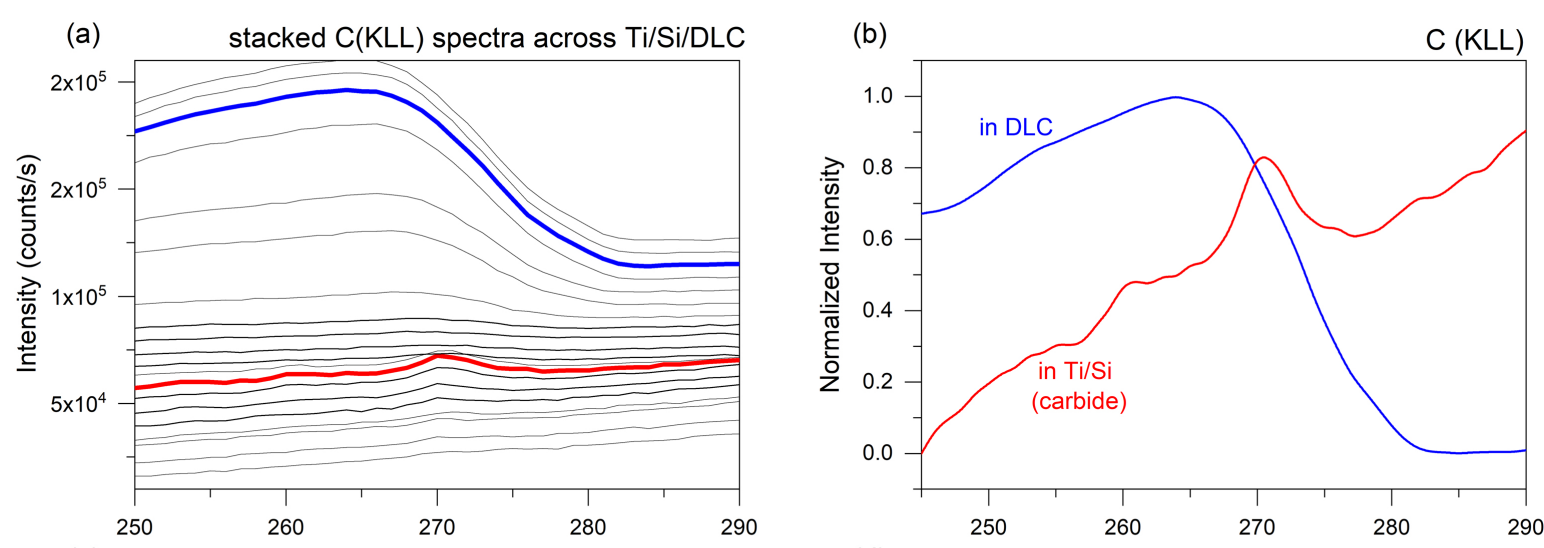

(c)

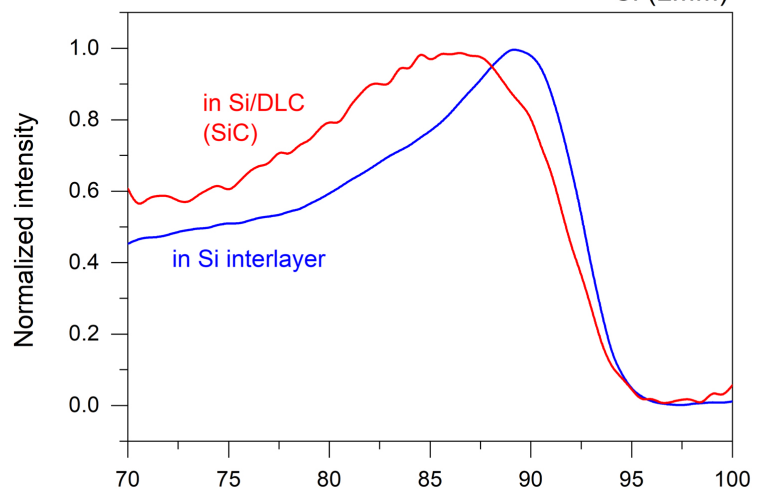

(d)

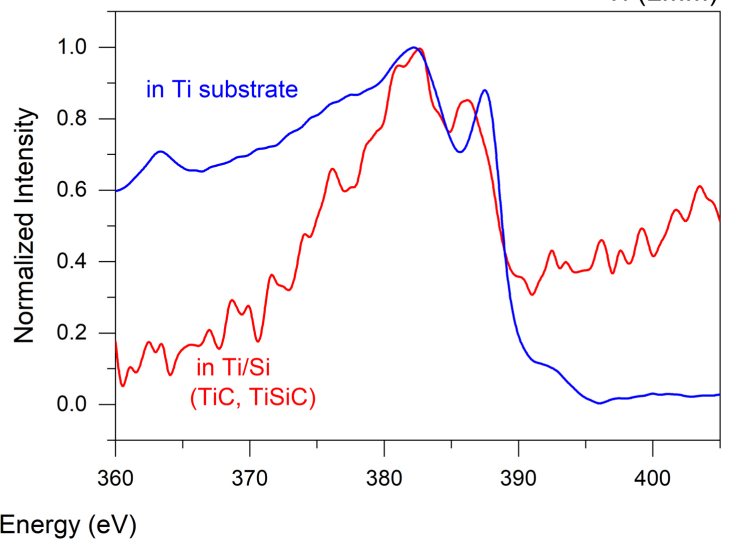

Figure 6 


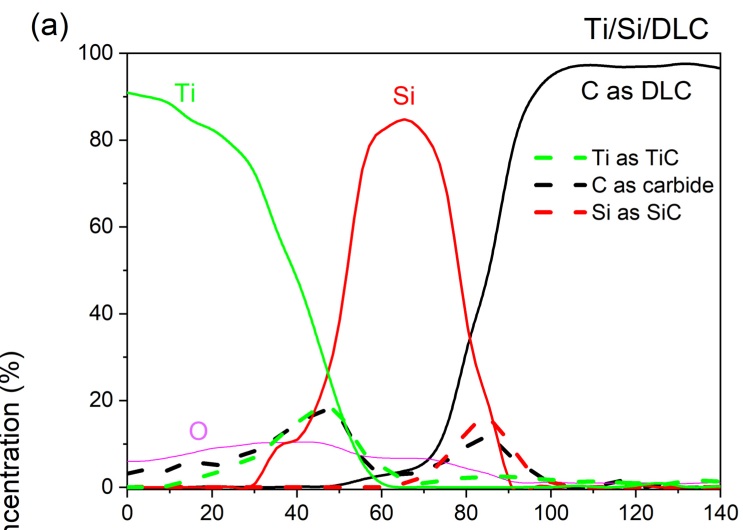

(b)

$\mathrm{Ti} / \mathrm{Cr} / \mathrm{DLC}$

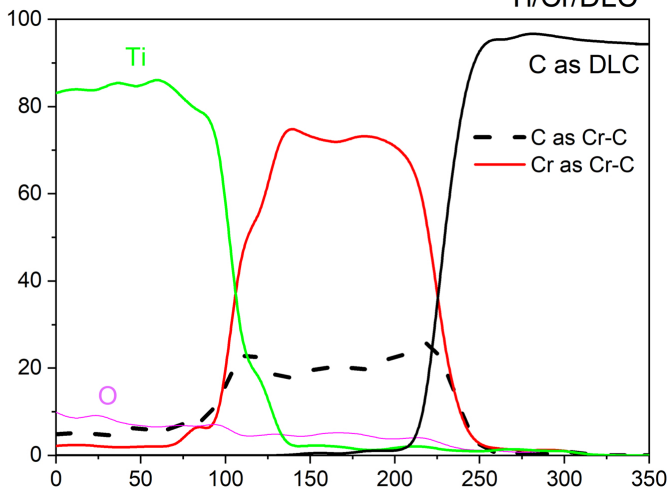

过

(c)

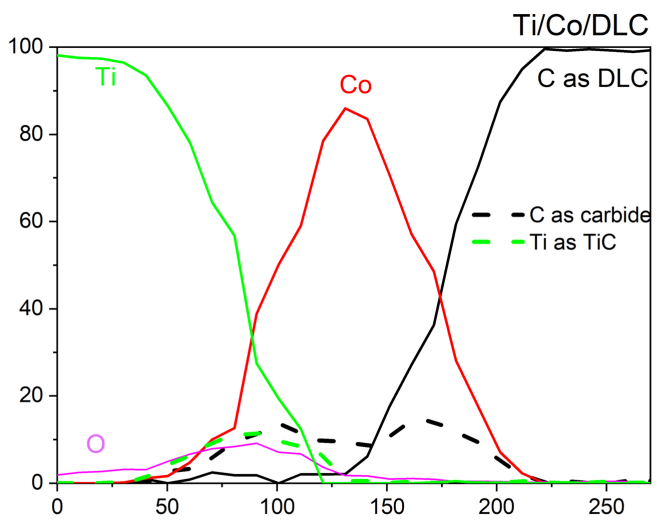

(d)

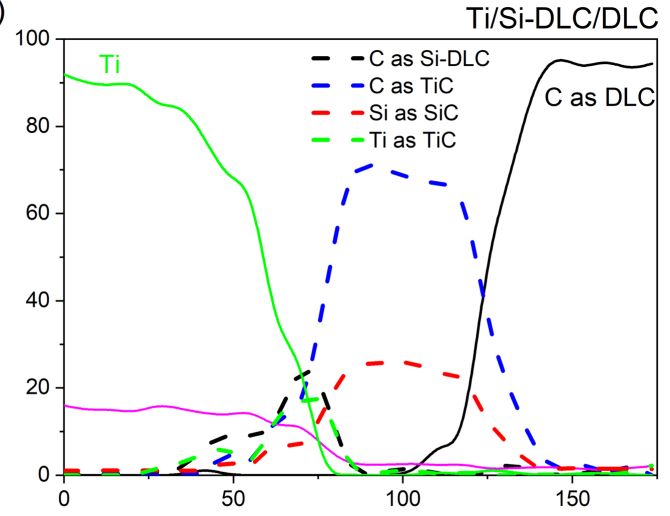

Distance $(\mu \mathrm{m})$

Figure 7 


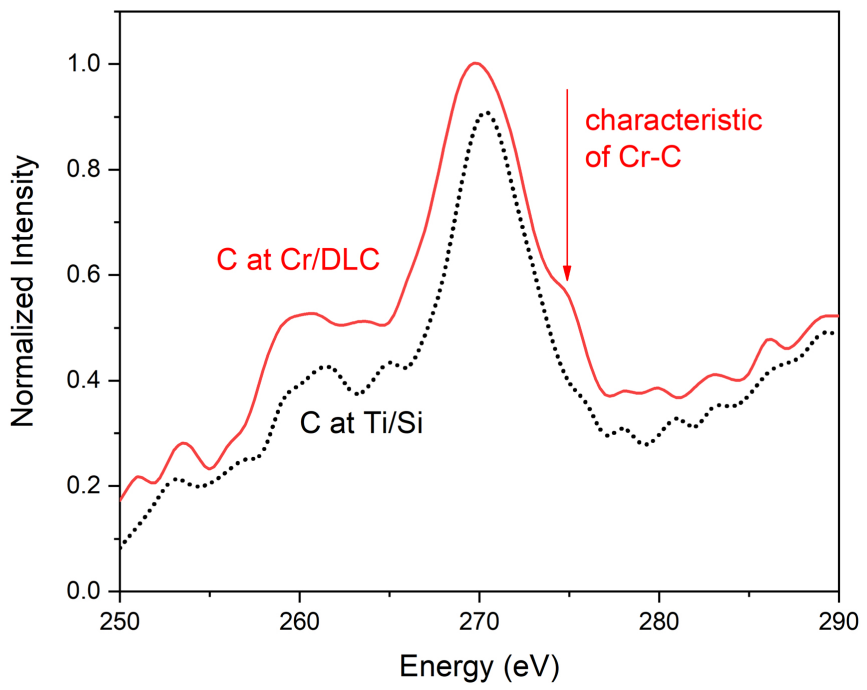

Figure 8 


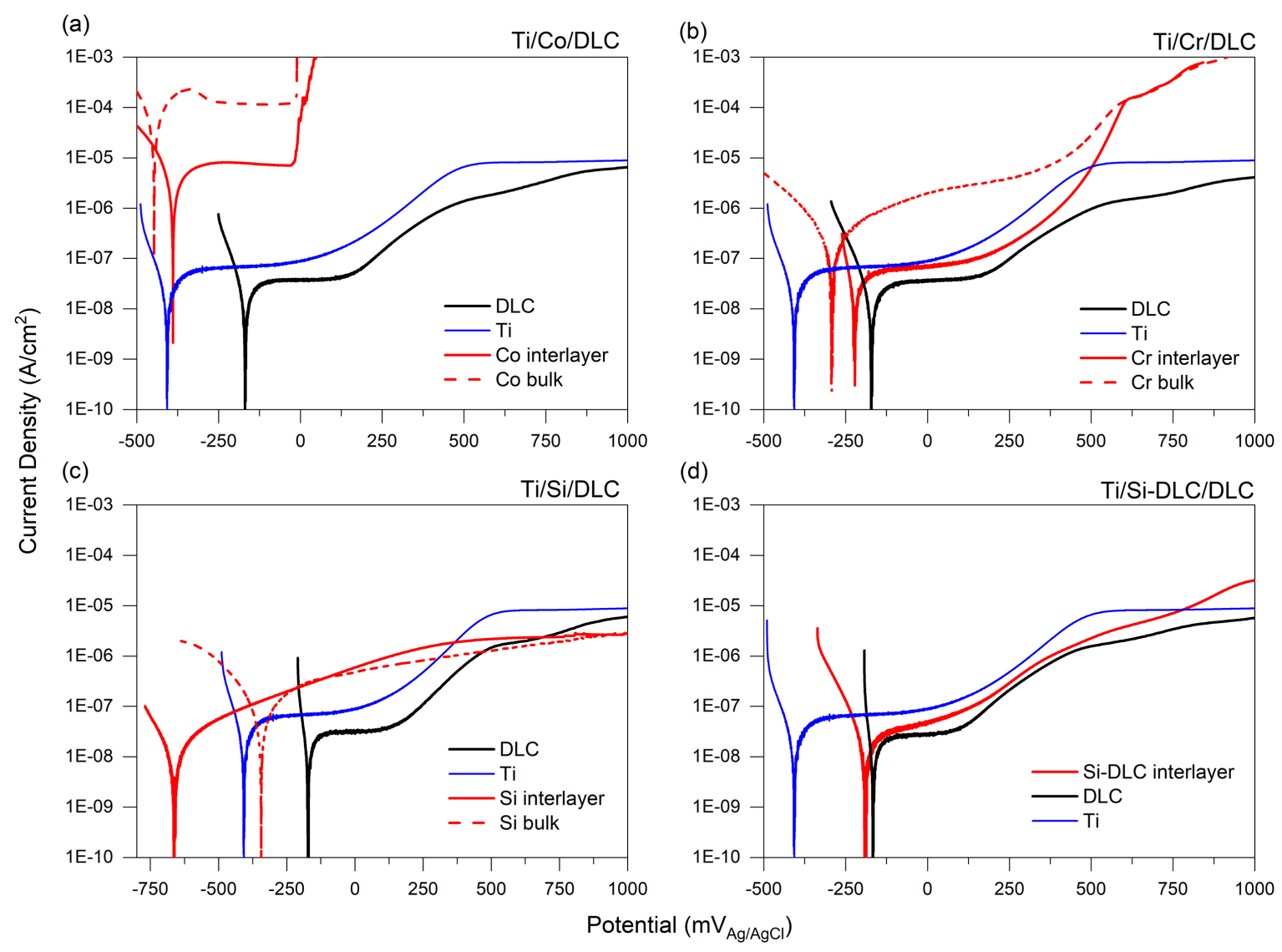

Figure 9 
(a)

(b)

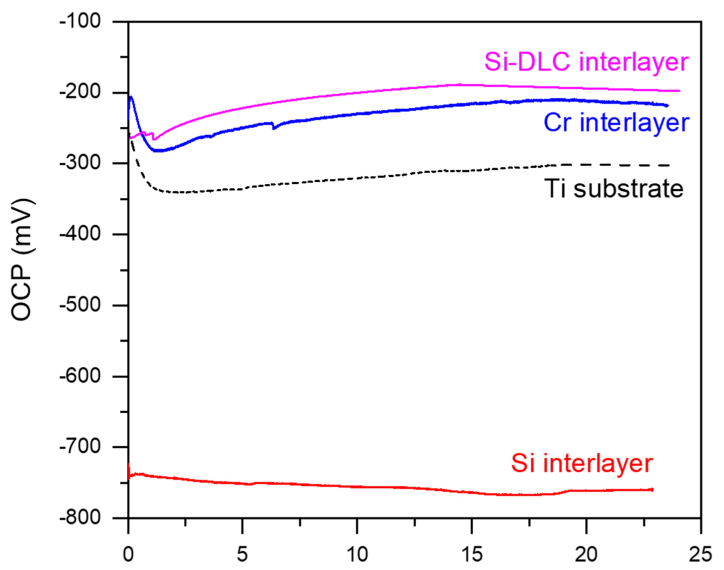

(b)

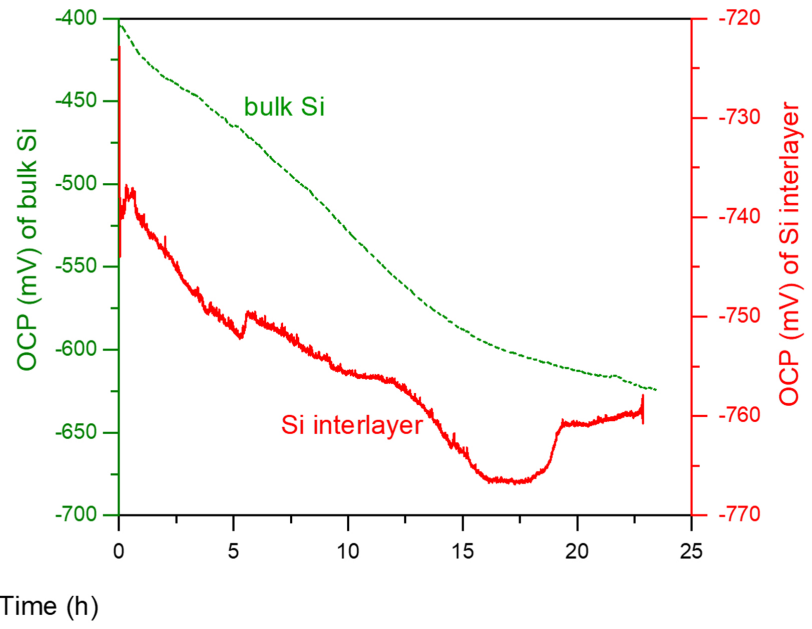

Figure 10 
a)
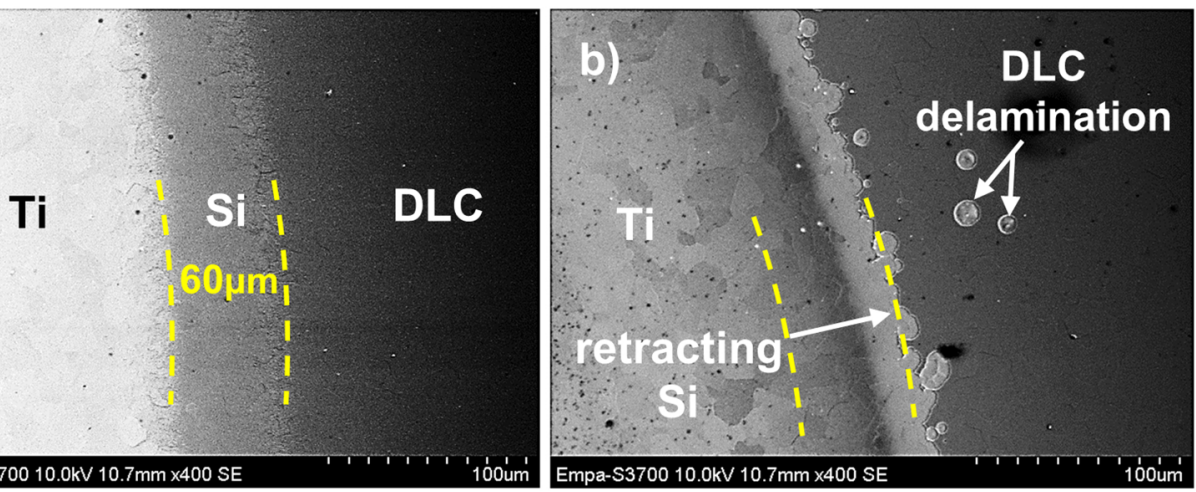

Figure 11 